\title{
Measuring The Factors Involved In The Time Spent In Educational Childcare
}

Maria-Angeles Medina, Complutense University, Spain

Gema Fernández-Avilés, University of Castilla-La Mancha, Spain

\begin{abstract}
Parents play an extremely important role in their children's lives and a plethora of research indicates that parents involvement is significantly related to positive child outcomes: Boys who feel that their parents devote time, especially to talk to them about their worries, school work and social lives, almost all emerge as motivated and optimistic men. More specifically, parents involvement in children's education at age 7 predicts higher educational attainment by age 20, in both boys and girls. Thus, parents involvement in children's education being considered a core factor for success in undergraduate education, in this paper we study the effect of parental socioeducational level on the time they spend in primary educational childcare (reading to children, teaching children, assistance with homework, attending meetings at a child's school, etc.). Given the low rate of success in the Spanish undergraduate education, we focus on the Spanish case. We focus on the Spanish case because we suspect that this factor can be one of the reasons for the low rate of success in the universities. Our study is based on the data provided by the Spanish Time Use Survey 2009-2010.
\end{abstract}

Keywords: Children's Education; Undergraduate Education; Parental Socio-Educational Level; 2009-2010 Spanish Time Use Survey

\section{INTRODUCTION}

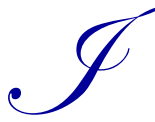
n time of crisis, as currently, paying special attentions to educational childcare becomes especially important, because future belongs to child. Society is changing the way we educate children and family structure where they grow. Some researchers claim that the development of a person depends on who and how you care in the first three years of life (Lamb, 2007). According to the work of González et al. (2010), couples in which both parents have college devote more time to the care of intellectual stimulation ("quality time").

In this paper, we will focus in time "quality" that parents spend reading and homework help to children. For this study, we use Spanish Time Use Survey (STUS) 2009-2010 conducted by National Statistics Institute, which uses an activities diary which reflects what the respondent is doing on a particular day every 10 minutes. GutierrezDomenech (2007) observed, using Spanish Time Use Survey (2002-03), which triple the mothers spent time parents (mothers 65 minutes, 26.86 parents) to take care of children but spent a similar time to the care quality (10 minutes). Many psychologists encourage parents to spend more time with their children in order to enrich them in their training. However, Meil (1997) shows that parent involvement with children does not depend on their profession or of their status, is what most influences whether women have a paid job, in that case, the time "does not work" is dedicated to women housework and the man to take care of children.

Our goal is to identify the sociological variables that most influence the parent's decision of exchange leisure time by childcare time. For this purpose, we will use the STUS surveys in which the individual states that this has been a "normal" day. First, we choose individuals. We select all households with more than one member, except childless couples. Then, from the "daily activities" elect the variables related to educational childcare. Although STUS distinguish between main and secondary activity, we will consider the time spend in educational childcare in as principal and/or secondary activity simultaneously. This choice is due to children needing both: (i) to have a presence active and (ii) to know that their parents are there if they have problems. Section 2 presents the 
methodology used to conduct the analysis. Section 3 describes the massive database. Section 4 shows the results. And finally, a brief section is devoted to present the conclusions.

\section{METHODS}

\subsection{The Classification Technique}

In order to classify the respondents taking into account the time spent in educational childcare, we are going to run classification trees. We use CHAID method (Kass, 1980). The acronym CHAID stands for Chi-squared Automatic Interaction Detector. CHAID is a type of decision tree technique, based upon adjusted significance testing (Bonferroni testing). Their interest lies mainly in their capacity to detect and account for non linear effects on the response variable, and especially of even high order interactions between predictors. As indicated by its name, CHAID uses a Chi-square splitting criterion. More specifically, it uses the $p$-value of the Chi-square.

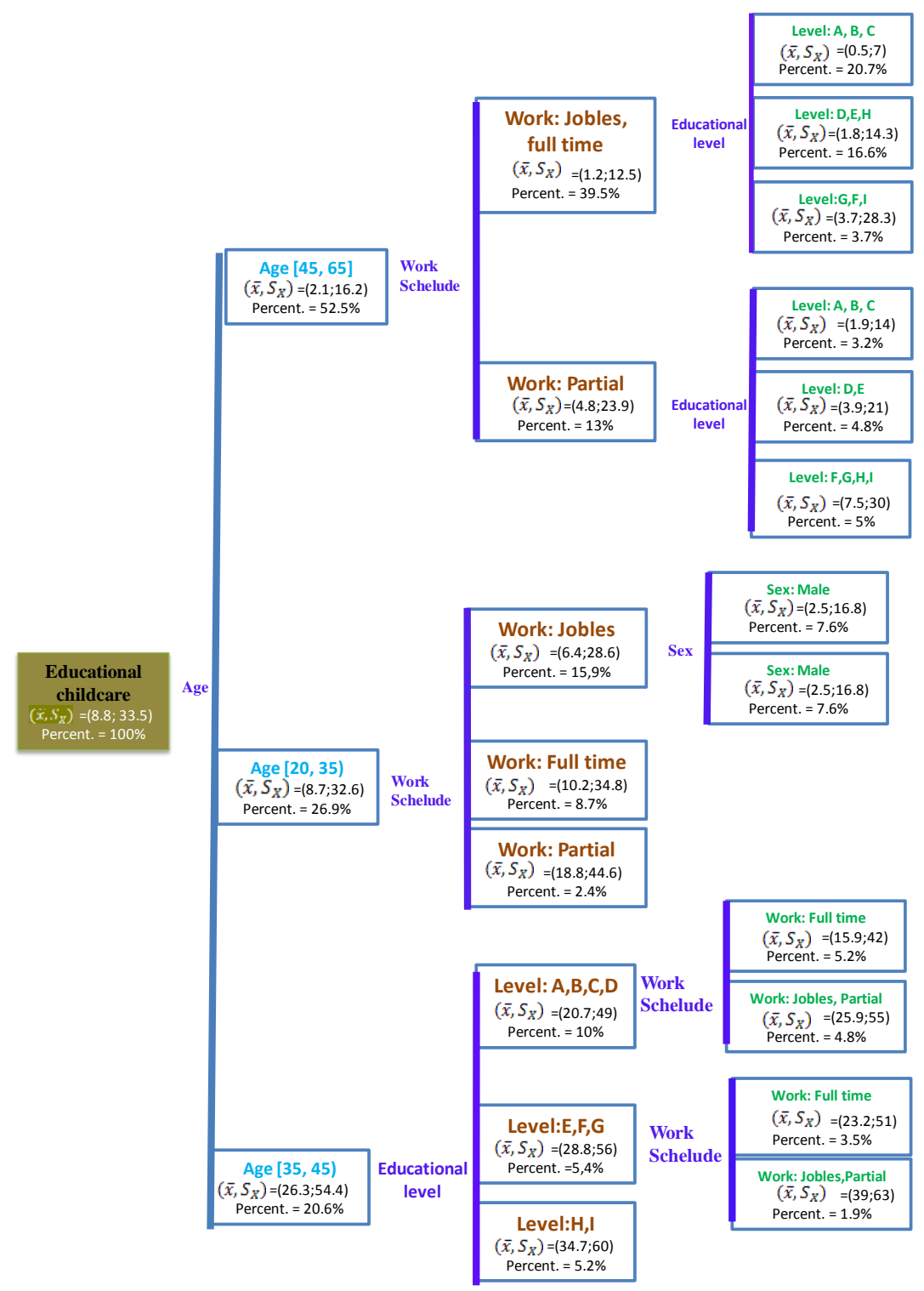

Figure 1: Classification Tree

Source: Own elaboration 
In this paper, the dependent variable is "Quality time in educational childcare" and de independent factors are the characteristics of the respondents. The three factors statistically significantly results "Age," "Work Schedule" and "Educational level" as you can see in Figure 1.

\subsection{The Model}

In order to identify the factors and the interactions of such factors that explain the variability of the success rate, we initially propose a linear model including three main factors and the corresponding interactions. In other words, we propose an analysis of variance (ANOVA) of three factors with interactions, the model being a nonbalanced fixed effects model as we have considered all the categories of the factors. More specifically the model we propose is given by:

$$
y_{i j k p}=\mu+\alpha_{i}+\beta_{j}+\delta_{k}+\sum_{\substack{a, b=i, j, k \\ a \neq b}} \gamma_{a b}+\gamma_{i j k}+\varepsilon_{i j k}, \quad i=1, \ldots, I ; j=1, \ldots, J ; k=1, \ldots, K ; p=1, \ldots, P
$$

where:

(i) $y_{i j k p}$ is the $p$ th observation in the $i$ th, $j$ th, $k$ th catergory of the first, second and third main factors, respectively.

(ii) $\mu$ is a general mean.

(iii) $\alpha_{i}, \beta_{j}, \delta_{k}$ represent the effects of the $i$ th level of the first factor, the $j$ th level of the second, $k$ th level of the third factor, respectively.

(iv) $\gamma_{a b}$ is the interaction effect for whichever two categories corresponding to (two) different factors, respectively.

(v) $\gamma_{i j k}$ indicates the interaction effects of the categories of the three factors included in the model.

In this work, the dependent variable, educational childcare, has been computed as the sum of the activities "Teaching the children" and "Reading, playing and talking with the children" that had been made as principal or secondary activities, measured in minutes.

The factors included in the model are Age, Work Schedule and Educational Level. Table 1 lists the categories of such factors.

Table 1: Factors Considered in the Study and Their Categories

\begin{tabular}{|l|l|l|}
\hline \multicolumn{1}{|c|}{ Age } & Work Schedule & \multicolumn{1}{c|}{ Educational Level } \\
\hline$[20-35)$ & Jobless & A: Uneducated \\
\hline$[35-45)$ & Partial-time & B: Incomplete primary education \\
\hline$[45-65)$ & Full-time & C: Primary education or the equivalent \\
\hline & $(34,40]$ & D: $1^{\text {st }}$ stage secondary education \\
\hline & $(40,45]$ & E: Post-secondary studies \\
\hline & & F: Intermediate-level professional education or the equivalent \\
\hline & & G: Advanced professional training or the equivalent \\
\hline & & H: First-cycle university studies or equivalent \\
\hline & & I: Second- or third-cycle university studies or equivalent \\
\hline
\end{tabular}

\subsection{Estimation and Testing}

Both the main and the interaction effects can be estimated using usual direct formulae as above or by using the least squares approach (the outcome is the same) (see Searle 1972). As for testing that there is no difference in the levels of the factors and in the first, second and third order interactions of the categories of such factors we use the traditional $F$-test. If the null is rejected, we use Tukey's Honest Significant Difference (HSD) for all pairwise comparisons to investigate which levels differ. 


\section{DATA}

The microdata we have used come from Spanish Time Use Survey (STUS) 2009-2010, which is based on the preceding Time Use Survey 2002-2003 and the new guidelines of the Harmonized European Surveys on Time Use compiled by Eurostat.

The three basic units of observation and analysis that are considered in STUS are (i) the individual members of the household aged 10 and above, (ii) private households residing in main family dwellings, (iii) the days of the week.

A household is defined as the ensemble of people who occupy a main family dwelling, or part of it, in common and consume and/or share food and other goods charged to the same budget. Each household selected in the sample is allocated a day of the week (from Monday to Sunday) to complete the activity diary. All household members aged 10 years old and over should complete the diary for the selected day. The diary timesheet covers 24 consecutive hours (from 6 a.m. to 6 a.m. the following day) and is divided into 10-minute intervals, in which the respondent has to note the main activity, the secondary activity (simultaneous) that he or she performed at the same time (where applicable), whether he or she was with other known persons at that time, where he or she was or the means of transport used, as well as whether or not he or she was using a computer or the Internet when performing these activities.

The size of the planned sample was around 11,538 dwellings, but after removing the empty dwellings and the dwellings that could not be sampled, the sample was reduced to 9,541 .

Finally, we work with 4,961 households, although only 1,878 of these households reported having devoted at least ten minutes to childcare activities the day they filled the one-day diary.

It is important to highlight, that the mean time devoted to educational childcare can be considered as scarce. Specifically, 58.02\% of respondent declared not spend even 10 minutes in educational childcare (Figure 2, Panel $a$ ). The distribution of people that spent at least 10 minutes in activities related to the education of children (41.98\% of the total) is shown in Figure 2, Panel b. Here the average time spend 81.3 minutes per day.

Panel $a$ : Distribution of Educational Childcare per Day

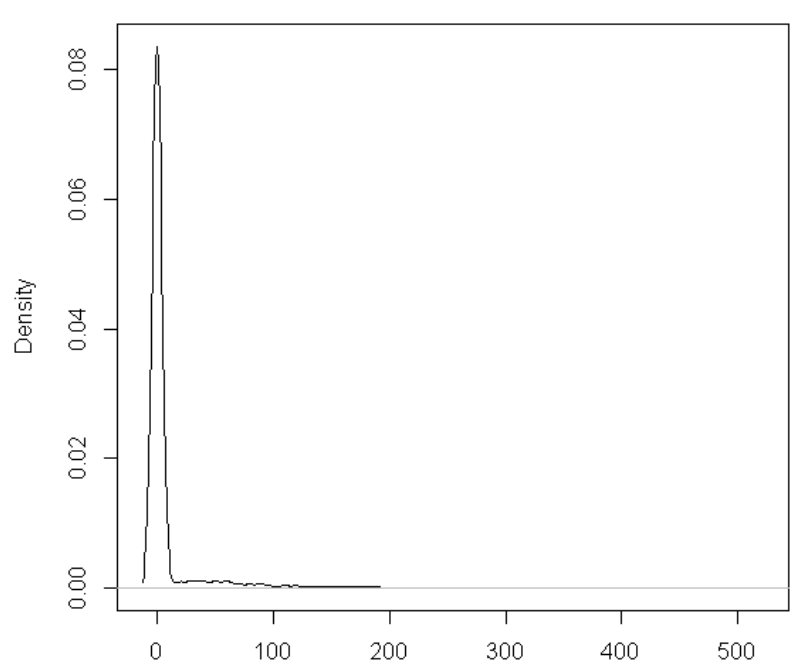

Panel $b$ : Distribution of People that Spend at least 10 Minutes in Educational Childcare per Day

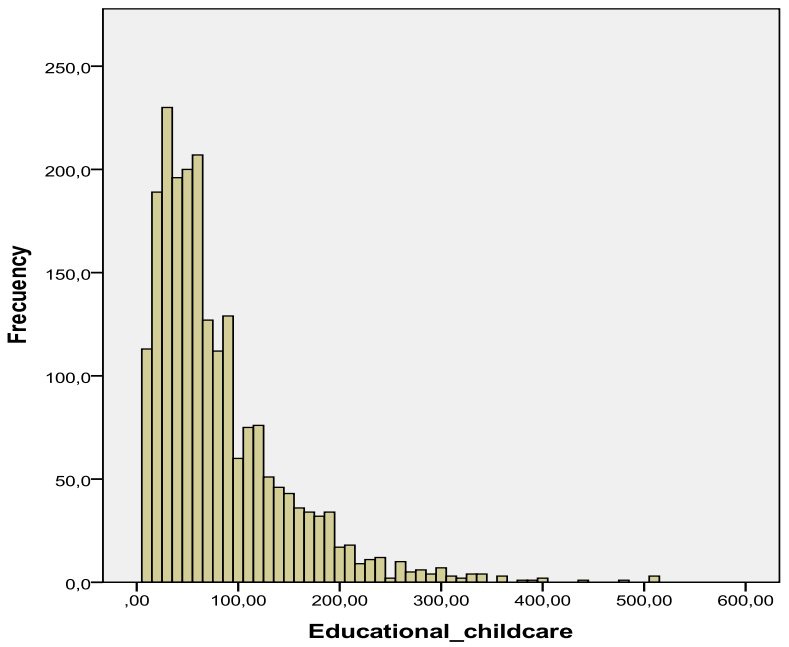

Figure 2: Distribution of Time in Educational Childcare

Source: Own elaboration

As can be seen in Figure 3, 27\% of respondents are between 20 and 34 years, $21 \%$ are between 35 and 44, and the remainder (52\% of the total) is between 44 and 65 years. As for work schedule, more than half of 
respondents (56\% of the total) are jobless, $8 \%$ of them have part-time work, $7 \%$ full-time work, $26 \%$ work between 34 and 40 hours per week, and 3\% said to work between 40 and 45 hours per week. Finally, putting our attention in the educational level of respondents, $4 \%$ is considered uneducated, $10 \%$ had incomplete primary education, $24 \%$ have primary education or the equivalent, $22 \%$ have 1 st stage secondary education, $13 \%$ have post-secondary studies (post-secondary graduate, secondary school, post-secondary non-higher education, pre-university), $5 \%$ have intermediate-level professional education or the equivalent, $6 \%$ have advanced professional training or the equivalent, $7 \%$ have first-cycle university studies or equivalent and the remainder, $9 \%$ of the total, studied secondor third-cycle university studies or equivalent.

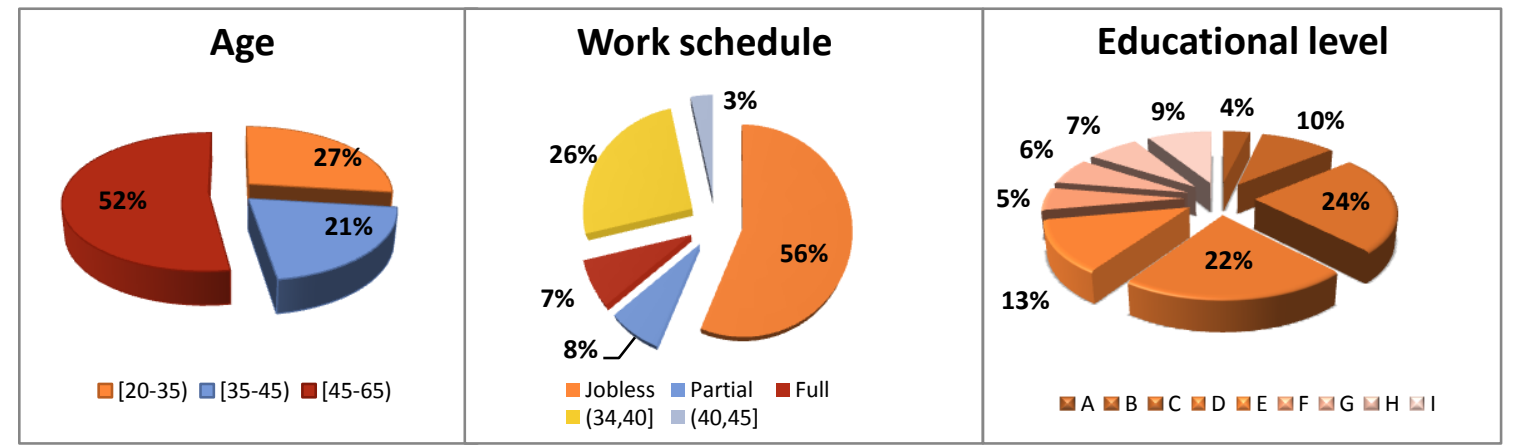

Figure 3: Percentage Distribution of the Exogenous Variables

Source: Own elaboration

Figure 4 depicts the plots of means corresponding to the categories of each of the three factors involved in our analysis. It can be easily appreciated that the mean and dispersion corresponding to the above mentioned modalities clearly indicate that the ANOVA of the data can be of interest to identify the sources of variation of the time spent in educational childcare of the Spanish people enrolled in the survey.
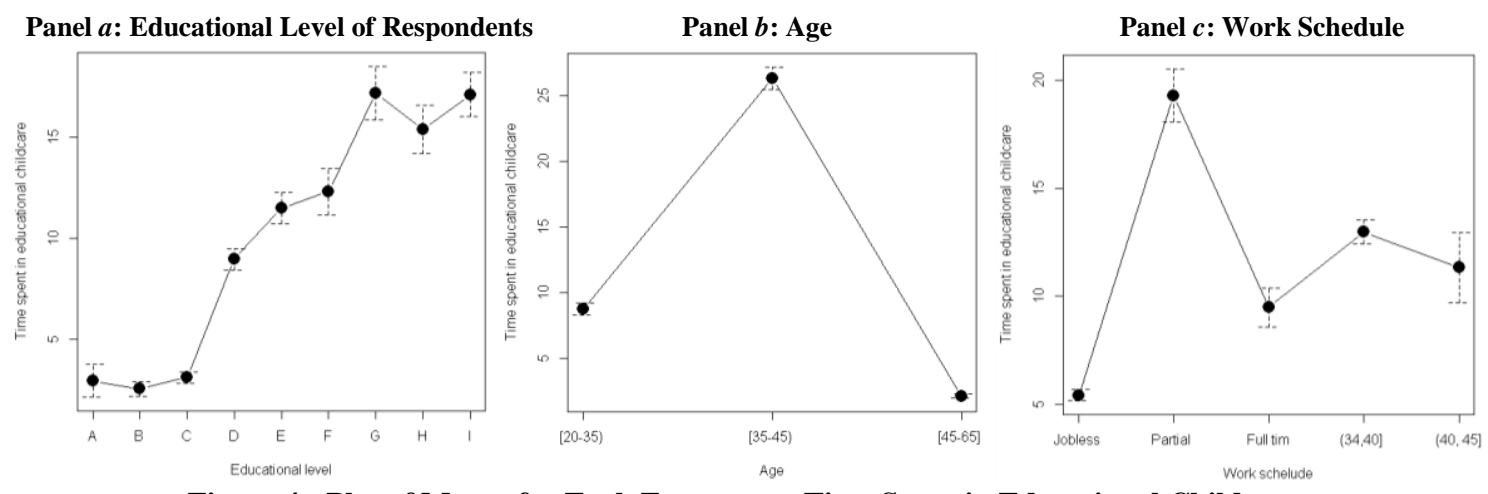

Figure 4: Plot of Means for Each Factor over Time Spent in Educational Childcare Source: Own elaboration

Checking the time spend in educational childcare with the three factors considered in the study two by two we obtain het map (an immediate visual summary of information). Figure 5 represents the intensity of educational childcare using colors, red indicate high activity, and light indicate low activity. Panel $a$ represents educational childcare with the factors educational level and age; Panel $b$ shows educational childcare with the factors educational level and work schedule; and Panel $c$ represents educational childcare with the factors work schedule and age. 


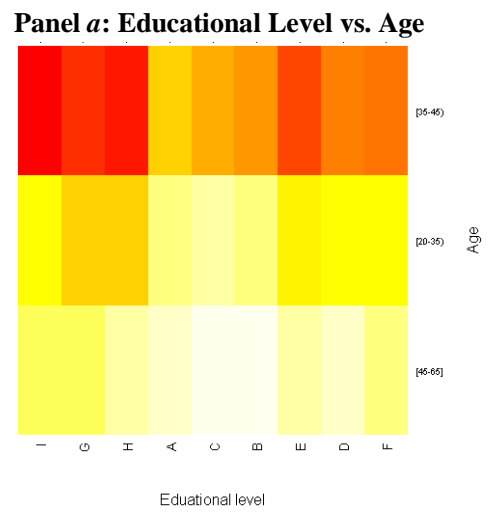

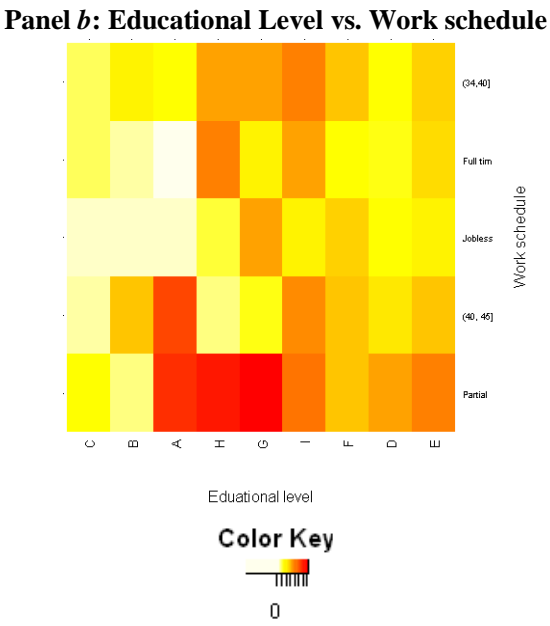

Figure 5: Heat Map of Educational Childcare Source: Own elaboration

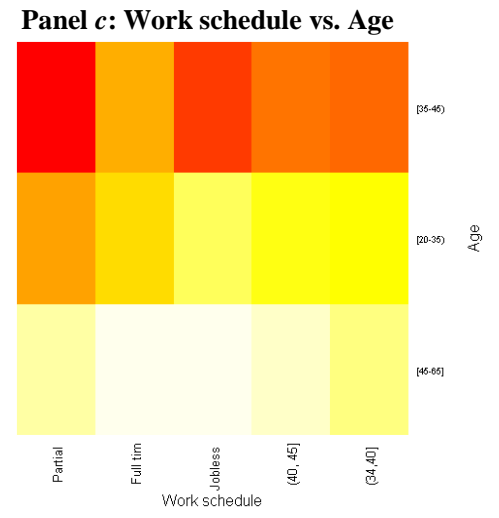

\section{RESULTS}

The time spent in educational childcare in Spain is around ten minutes each day, exactly 8.8 minutes per day (with a standard deviation of 33.3 minutes). However, as it can be seen in Table 2, the ANOVA of our data reveals that all the main factors involved in Model (1) are statistically significant: Age, educational level and work schedule. In fact, they are highly significant (the $p$-values are < 2.2E-16 for the two first factors and $6.994 \mathrm{e}-13$ for the last one). This means that at least two age intervals yield significantly different results in the educational childcare. The same occur with the factors educational level and work schedule, with a high degree of significance.

Table 2: Analysis of Variance. Response Variable: Educational Childcare

\begin{tabular}{llcccccc}
\hline & & Df & Sum Sq & Mean Sq & $\boldsymbol{F}$ value & Pr(> F) \\
\hline & Age & 2 & 1676174 & 838087 & 830.8504 & $<2.2 \mathrm{e}-16 * * *$ \\
Main factors & Educational level & 8 & 156708 & 19589 & 19.4194 & $<2.2 \mathrm{e}-16 * * *$ \\
& Work schedule & 4 & 63587 & 15897 & 15.7594 & $6.994 \mathrm{e}-13 * * *$ \\
& Age \& Educational level & 16 & 79777 & 4986 & 4.943 & $2.567 \mathrm{e}-10 * * *$ \\
$\begin{array}{l}\text { First order } \\
\text { interactions }\end{array}$ & Age \& Work schedule & 8 & 111197 & 13900 & 13.7796 & $<2.2 \mathrm{e}-16 * * *$ \\
$\begin{array}{l}\text { Second order } \\
\text { interactions }\end{array}$ & Educational level \& Work schedule & 32 & 67089 & 2097 & 2.0784 & $0.0003318 * * *$ \\
Residuals & Age \& Educational level \& Work schedule & 62 & 115907 & 1869 & 1.8533 & $5.340 \mathrm{e}-05 * * *$ \\
\hline
\end{tabular}

*** significant at the 0.001 level; ** significant at the 0.01 level; * significant at the 0.05 level; . significant at the 0.1 level. Source: Own elaboration.

In light of the Tukey's (HSD) test for the all pairwise comparisons of the levels of the factor "Educational level" (Table 3), as expected, the largest differences are that of categories G (Advanced professional training or the equivalent), H (First-cycle university studies or equivalent) and I (Second- or third-cycle university studies or equivalent), the higher level of studies, with the rest of categories because these are at the top of the ranking of time spend in educational childcare (17.2 minutes per day with a standard deviation of 46.9 minutes, 15.3 minutes per day with a standard deviation of 43.4 minutes and 17.1 minutes per day with a standard deviation of 45.1 minutes, respectively). Specifically, the categories G, H and I exceed in mean, around: (i) 6 minutes per day about category A (uneducated), (ii) 7 minutes category B (incomplete primary education), and (iii) 8 minutes category C (Primary education or the equivalent), the rest are not statistically significant.

As for factor "Work schedule", unsurprisingly, the largest difference is that of category partial-time with full-time (8,6 minutes per day). Partial-time is in the top of the ranking of the factor work schedule, with 29.3 minutes per day in educational childcare with standard deviation 47.2 minutes. The difference between partial-time and the rest of categories is also statistically significant. 
Regarding factor "Age," all possible difference are statistically significant. The biggest difference (24.2 minutes per day) is between the intervals [45-65) years and [35-45) years.

Table 3: Tukey HSD (Multiple Comparisons of Means)

\begin{tabular}{|c|c|c|c|c|c|c|c|c|c|}
\hline \multicolumn{5}{|c|}{ Age } & \multicolumn{5}{|c|}{ Educational Level } \\
\hline & diff & lwr & upr & p-adj & & diff & lwr & upr & $p$-adj \\
\hline$[20-35)-[35-45)$ & -17.6147 & -19.1831 & -16.0463 & 0.0000 & G-A & 5.9827 & 1.3514 & 10.6139 & 0.0020 \\
\hline$[45-65)-[35-45)$ & -24.2306 & -25.6239 & -22.8373 & 0.0000 & H-A & 5.9368 & 1.3787 & 10.4948 & 0.0018 \\
\hline$[45-65)-[20-35)$ & -6.6159 & -7.8862 & -5.3456 & 0.0000 & I-A & 6.5771 & 2.1825 & 10.9718 & 0.0001 \\
\hline & & & & & E-B & 3.4660 & 0.4902 & 6.4418 & 0.0092 \\
\hline & & & & & G-B & 6.5988 & 3.0392 & 10.1585 & 0.0000 \\
\hline \multicolumn{5}{|c|}{ Work Schedule } & H-B & 6.5529 & 3.0891 & 10.0168 & 0.0000 \\
\hline & diff & lwr & upr & p-adj & I-B & 7.1933 & 3.9474 & 10.4392 & 0.0000 \\
\hline Full time-(34-40] & -2.3903 & -4.9874 & 0.2068 & 0.0882 & D-C & 2.2231 & 0.1197 & 4.3266 & 0.0290 \\
\hline Partial-(34-40] & 6.2008 & 3.6148 & 8.7868 & 0.0000 & E-C & 4.0896 & 1.6159 & 6.5634 & 0.0000 \\
\hline Partial-(40-45] & 7.4082 & 3.3184 & 11.4980 & 0.0000 & G-C & 7.2225 & 4.0705 & 10.3745 & 0.0000 \\
\hline Jobless-Full time & 2.6152 & 0.1843 & 5.0462 & 0.0276 & H-C & 7.1766 & 4.1332 & 10.2200 & 0.0000 \\
\hline Partial-Full time & 8.5911 & 5.3699 & 11.8124 & 0.0000 & I-C & 7.8169 & 5.0242 & 10.6097 & 0.0000 \\
\hline \multirow[t]{8}{*}{ Partial-Jobless } & 5.9759 & 3.5568 & 8.3950 & 0.0000 & G-D & 4.9994 & 1.8182 & 8.1805 & 0.0000 \\
\hline & & & & & H-D & 4.9535 & 1.8798 & 8.0271 & 0.0000 \\
\hline & & & & & I-D & 5.5938 & 2.7682 & 8.4195 & 0.0000 \\
\hline & & & & & H-E & 3.0870 & -0.2510 & 6.4249 & 0.0964 \\
\hline & & & & & I-E & 3.7273 & 0.6162 & 6.8385 & 0.0063 \\
\hline & & & & & G-F & 4.6627 & 0.5387 & 8.7867 & 0.0135 \\
\hline & & & & & H-F & 4.6168 & 0.5752 & 8.6584 & 0.0118 \\
\hline & & & & & I-F & 5.2571 & 1.4007 & 9.1135 & 0.0008 \\
\hline
\end{tabular}

Legend: diff: difference in the observed means; lwr: lower end point of the interval; upr: upper end point; and $p$-adj: $p$-value after adjustment for the multiple comparisons. Source: Own elaboration.

Respecting the interaction effects, it has been found a highly significant first order interaction between the three main factors (significant at a 0.01 confidence level). Specifically, between respondent between [20-35) years and second- or third-cycle university studies or equivalent and the same range of years with first-cycle university studies or equivalent, which dedicate 8.9 and 14.0 minutes to educational childcare per day. The same range of age is significant with full time work (at a 0.05 confidence level) and with work schedule of (40-45) hours per week (at a 0.05 confidence level). About the level of studies, the interaction between the categories 1 st stage secondary education and post-secondary studies and jobless are significant al 0.01 confidence level, been 8.3 and 9.3 minutes per day the time devote to educational childcare, respectively.

As for the second order interactions, it has been found significant interactions between the responders between [20-35) years, full-time work and level of studies primary education or the equivalent, 1st stage Secondary Education and post-secondary studies, with only around ten minutes educational childcare per day. Something similar could be said in the interval [45-65) years, jobless, and level of studies 1st stage secondary education and post-secondary studies.

\section{CONCLUSIONS}

It is important to determine the factors that influence the time spent on children in educational activities. As you know, this result is directly related in the future of student.

First of all, we would like to highline that the STUT 2009-2010 shows a very poor result when we ask for the time spent in educational childcare. More than half of responder said don't dedicate any minute to this important activity. 
After a laborious process of classification with decision trees, we have selected three factors: age, work schedule and educational level of the household. All the main factors are statistically significant (0.01 significant level) and the first and second order interactions (also with 0.01 significant level).

As expected, high level education in household is directly associated with more time spent in educational childcare. Also, a part-time work and the people who are jobless are directly associated with spent time in educational childcare. Regarding the age factor, the interval [35-45) is that more time dedicate to educational childcare.

Concerning the profile which more time spent in educational childcare, the following combinations have been obtained: (i) Age between 35 and 45 years, part-time work and advanced professional training or the equivalent study level with 54 minutes per day in mean; (ii) Age between 35 and 45 years, partial-time work and first-cycle university studies or equivalent level with 51 minutes per day in mean; and (iii) Age between 35 and 45 years, work schedule between 40 and 45 hours per week and the higher educational level (second- or third-cycle university studies or equivalent) with 50 minutes per day in mean and (iv) Age between 35 and 45 years, work schedule between 40 and 45 hours per week and uneducated with 50 minutes per day in mean.

On the contrary, the lower values in mean are for the combinations: (i) Age between 45 and 65 years, fulltime and uneducated; (ii) Age between 45 and 65 years, part-time and uneducated; (iii) Age between 20 and 35 years, full-time and incomplete primary education; (iv) Age between 45 and 65 years, part-time and incomplete primary education, in all cases without devoting no time to childcare education.

\section{AUTHOR INFORMATION}

María-Ángeles Medina is a Lecturer in Statistics at Statistics Department, Faculty of Statistical Studies, Complutense University of Madrid, Spain. Maria-Angeles' research interests include multivariate analysis, use of time, and gender. E-mail: amedina@ucm.es

Gema Fernández-Avilés holds a PhD in Statistics and teaches in the Statistics Department, Faculty of Social Sciences of Toledo, University of Castilla-La Mancha, Spain. Dr. Fernandez-Aviles' research interests include spatial statistics, environment and air pollution, geostatistics, education, regional analysis, decision theory and gender. Webpage: http://www.uclm.es/profesorado/gemafaviles/ E-mail: gema.faviles@uclm.es (Corresponding author)

\section{REFERENCES}

1. González, M. J., Domínguez, M., \& Baizán, P. (2010). Cuidado parental en la infancia y desigualdad social: un estudio sobre la Encuesta de Empleo del Tiempo en España (In Spanish).

2. Gutiérrez-Domènech, M. (2007). El tiempo con los hijos y la actividad laboral de los padres. Documentos de Economía, la Caixa (In Spanish).

3. Instituto Nacional de Estadística (2011). Encuesta de Empleo del tiempo 2009-2010. Metodología. Retrieved from http://www.ine.es/metodologia/t25/t25304471.pdf

4. Kass, G. V. (1980). An exploratory technique for investigating large quantities of categorical data. Applied Statistics, 29(2), 119-127.

5. Lamb, M. E. (2007). Nonparental child care: Context, quality, correlates, and consequences. In: I. E. Sigel \& K. A. Renninger, eds. Child psychology in practice (pp. 73-134). New York, NY: J. Wiley; 1998. Damon W, ed-in-chief. Handbook of Child Psychology (5th ed.). Vol 4.

6. Meil, G. (1997). La participación masculina en el cuidado de los hijos en la nueva familia urbana española. Papers Universidad Autónoma de Madrid, 77-99 (In Spanish).

7. $\quad$ Searle, S. R. (1972). Linear models. Wiley: New York. 